\section{Развитие корпоративной социальной ответственности \\ в посткоммунистических странах ${ }^{1}$}

И.Ю. БЛАМ, кандидат экономических наук,

Институт экономики и организации промышленного производства СО РАН. E-mail: inna@ieie.nsc.ru

К. БОРСЕКОВА, кандидат экономических наук

Университет Матей Бел, Банска Быстрица, Словакия.

E-mail: kamila.borsekova@umb.sk

К. ПЕТРИКОВА, кандидат экономических наук

Университет Матей Бел, Банска Быстрица, Словакия.

E-mail: katarina.vitalisova@umb.sk

М. соколович, кандидат экономических наук,

Университет г. Лодзь, Польша.

E-mail: mariusz.sokolowicz@uni.lodz.pl

Статья посвящена проблемам становления института социальной ответственности бизнеса в посткоммунистических странах. Предпринята попытка сравнительного анализа роли градообразующих предприятий в социальном развитии так называемых монопрофильных поселений в Польше, России и Словакии. По мнению авторов, при всём богатстве форм социально ответственного поведения во всех этих государствах наблюдается тенденция постепенной утраты градообразующими предприятиями исторически навязанной им патерналистской роли гарантированных поставщиков социальной защиты. Происходит постепенная трансформация традиционной модели взаимодействия предприятий и локального сообщества в более современные формы корпоративно-социальной ответственности, основанные на добровольном участии в социально-экономическом развитии населенных пунктов и регионов присутствия. Ключевые слова: корпоративная социальная ответственность, посткоммунисти ческие страны, институты, государственное регулирование

1 Статья подготовлена в рамках исследовательского проекта № FP7-PEOPLE-2011 IRSES295050 «Функционирование локальных производственных систем в условиях экономического кризиса», финансируемого в рамках 7-й Рамочной программь Европейского союза (Functioning of the Local Production Systems in the Conditions of Economic Crisis (Comparative Analysis and Benchmarking for the EU and Beyond) (FOLSPEC), funded by the 7th Framework Programme of the EU).

\section{Социальная ответственность \\ в плановой экономике}

Социально ответственное поведение бизнеса ${ }^{2}$ не является исключительно современным трендом. История сохранила память о деятельности многих фабрикантов-меценатов, за счет собственных средств развивавших городскую инфраструктуру, предоставлявших локальные общественные блага и социальные услуги на территории функционирования предприятия.

Стартовые условия развития социально ответственного поведения в монопрофильных поселениях посткоммунистических стран в большинстве случаев значительно отличались от распространенных в XX в. в Северной Америке и Западной Европе. Так, характерной чертой моногородов Советского Союза была неразрывная связь населенного пункта и градообразующего предприятия, реализующего не только экономические, но и социальные функции, обеспечивая своих работников ведомственным жильем, детскими садами, поликлиниками, учебными и культурными учреждениями. Во избежание социального напряжения градообразующие предприятия во многих случаях продолжают поддерживать жилищно-коммунальную, транспортную и культурно-досуговую инфраструктуры всего населенного пункта.

Ситуация, когда градообразующие предприятия вкладывают значительные средства из собственной прибыли с целью поддержания достойного уровня городской среды, представлялась весьма необычной сторонним наблюдателям, находящимся вне политической и культурной традиции. Так, описывая нефтяную промышленность Советского Союза после разрушения «железного занавеса», Густафсон [2] особое внимание уделил ее уникальности с точки зрения социальной ответственности (при экономической неэффективности): «Когда был поднят “железный занавес", могло показаться, будто неожиданно вступили в контакт

2 Понимание социально ответственного поведения бизнеса варьируется в весьма широких пределах - от строгого выполнения требований действующего законодательства до реализации взятых на себя добровольных обязательств в социальной, природоохранной и этической сферах путем модификации стратегий производственной и коммерческой деятельности. В нашей статье мы будем опираться на следующее определение корпоративной стратегии социально ответственного бизнеса: «социально ответственной может быть названа компания, предпринимающая не продиктованные коммерческими нуждами и требованиями рынка шаги в интересах своих стейкхолдеров» [1]. 
две чуждые друг другу цивилизации с разных планет... Культурный шок был экстремальным, причем для обеих сторон... На месторождениях и, в особенности, в городках нефтяников превалировала культура, во многих аспектах противоположная ценностям нового капитализма. “Нефтяные генералы”, которые руководили советскими месторождениями и нефтеперерабатывающими заводами, были патерналистскими фигурами и отвечали не только за эффективность работы своих подчиненных, но также за их жильё, свет и воду, да и за всю их жизнь целиком. Рутинно практикуемые работодателями на Западе безжалостные мероприятия по сокращению издержек и штатов, разукрупнение и аутсорсинг противоречили самой природе сплочённых советских нефтяных моногородов. Стремление частных предпринимателей всячески “оптимизировать” добычу (абсолютно нормальное явление на Западе, который верит в то, что “нефть сегодня ценится дороже, чем нефть завтра") порождало подозрения в скором истощении месторождений, способном подорвать основу жизни целых городских сообществ».

История закрытия Байкальского целлюлозно-бумажного комбината ярко иллюстрирует степень зависимости населения монопрофильного города и городской инфраструктуры от градообразующего предприятия. Построенный в 1960-х годах комбинат считался крупнейшим источником загрязнения Байкала, в связи с чем природоохранные организации в течение длительного времени препятствовали его нормальному функционированию и настаивали на прекращении варки целлюлозы. В итоге осенью 2013 г. было принято решение о поэтапной остановке производства. Помимо безработицы и сопутствующей социальной напряженности возникла проблема поддержания функционирования объектов жизнеобеспечения города - теплоэлектростанции, очистных сооружений, горячего и холодного водоснабжения, которые не просто всегда принадлежали комбинату, но входили в структуру его производственных мощностей (за единственным исключением - в 2008 г. одновременно с созданием системы замкнутого водооборота комбината были построены городские канализационно-очистные сооружения). Даже городской мусор из Байкальска вывозился на одну из законсервированных карт комбината [3].
Отличие начальных условий и, как следствие, процессов становления и развития социальной ответственности российского бизнеса нашло отражение в нефинансовой отчетности компаний. Во всем мире публикация данных о социально ответственном поведении бизнеса началась в 1990-х годах с экологических отчетов, что было связано с растущей озабоченностью общества качеством окружающей среды и рациональным использованием природных ресурсов. Россия же оказалась вне глобального тренда: отечественные компании опубликовали первые экологические отчеты десятью годами позже, в начале 2000 -х, хотя отдельные данные, которые сейчас принято включать в нефинансовые отчеты, собирались и анализировались советскими предприятиями на регулярной основе.

Таким образом, многие элементы социальной отчетности (и, следовательно, социально ответственного поведения) зачастую хорошо знакомы «старым» российским компаниям ещё из практики их работы в Советском Союзе, хотя сбор подобной информации тогда преследовал иные цели [4].

Заметим, что в плановых экономиках инвестиции доминирующего предприятия в персонал, социальные и инфраструктурные объекты часто были обусловлены производственной необходимостью, поскольку позволяли обеспечить производство квалифицированными кадрами. В иных случаях навязанная «сверху» социальная ответственность способствовала сохранению неэффективной экономической структуры и истощала ресурсы предприятия.

Необходимость сохранения экономического значения градообразующих предприятий в ходе вынужденных трансформационных процессов стала причиной значительного сокращения неэффективных расходов компаний в посткоммунистических странах. Поддержание конкурентоспособности предприятий, ставшее в переходный период первоочередной задачей, потребовало смягчения бремени неформальной социальной нагрузки и формирования новых принципов взаимодействия с государством в части обеспечения функционирования и развития населенного пункта размещения. 


\section{Моногорода в экономике России, Польши \\ и Словакии}

Социальная ответственность градообразующих предприятий ввиду их значимой роли в экономике России заслуживает особого внимания: в 2008 г. около 40\% городских населенных пунктов могли быть отнесены к категории моногородов, при этом доля производимого ими ВВП также составляла около $40 \%$ от ВВП Российской Федерации [5]. В Польше и Словакии, которые наряду с Россией будут рассмотрены в данной статье, термин «моногород» не используется явно, хотя малые города с доминированием одного предприятия или одной экономической функции встречаются достаточно часто. В основном это малые и средние города, которые можно разделить на три группы:

- города, являющиеся центрами сельскохозяйственных районов;

- города-спутники крупных промышленных центров, входящие в состав городской агломерации;

• города со специализированной экономической экзогенной функцией [6].

В России до выхода постановления Правительства РФ от 29.07.2014 г. моногородами было принято называть населенные пункты с действующим градообразующим предприятием (согласно определению федерального закона «О банкротстве» градообразующим считается предприятие, на котором занято не менее $25 \%$ всего работающего населения), а также поселение, в котором не менее $50 \%$ производящейся в нем продукции относится к одной отрасли [7].

Согласно данному постановлению, моногородом в России может быть признано муниципальное образование, имеющее статус городского округа или городского поселения с численностью постоянного населения более 3 тыс. чел. При этом необходимо выполнение хотя бы одного из двух условий - либо численность работников одного из промышленных предприятий моногорода составляет более 5 тыс. чел., либо свыше $20 \%$ экономически активного населения заняты на единственном предприятии.

В официальный список моногородов России, не являющийся на данный момент окончательным, включены все закрытые административно-территориальные образования. При этом поселения, в которых в соответствии с региональным законом находится представительный орган региона России, а также нефтяные и газовые города, не могут быть отнесены к монопрофильным (http://www.rbc.ru/economics/22/01/2014/900788.shtml).

Хотя с методологической точки зрения указанные критерии не выдерживают никакой критики, они соответствуют основным целям анонсированного национального проекта по развитию моногородов, к которым можно отнести снижение уровня безработицы и зависимости от градообразующего предприятия.

В Словакии, Польше и России моногорода в основном появились в связи с развитием новых производств. Так, например, в XIX в. в результате объединения шести независимых поселений вокруг вновь созданного чугунолитейного завода в долине реки Грон возник словацкий город Подбрезова.

В 1930-х годах весьма популярной была идея комплексного развития территорий (многие монофункциональные города России были созданы именно в это время в процессе формирования территориально-производственных комплексов), нашедшая воплощение и в планах польского правительства. Многие моногорода Подкарпатья, юго-восточного региона Польши, были созданы в рамках Проекта промышленного развития центрального округа с целью индустриализации этой части страны. Именно тогда города Кросно, Мелец Дембица и Сталёва-Воля превратились в центры стекольной, химической, авиационной, строительной и металлургической промышленности соответственно.

Проект развития центрального индустриального округа - один из крупнейших экономических проектов Второй Польской Республики, задачами которого было развитие тяжелой промышленности, усиление экономики и сокращение безработицы. Реализации четырехлетнего плана развития региона, утвержденного 1 сентября 1936 г., помешала война. Однако в 1945 г. проект был возрожден и расширен Польской Народной Республикой. Выбор территории реализации проекта был обусловлен ее относительной удаленностью от границ страны, высокой плотностью населения в сочетании с превышающим средний по стране уровнем безработицы, а также наличием ресурсов для развития сельского хозяйства, промышленности и энергетического сектора [8].

Словацкие монопрофильные поселения Свит и Партизанске были созданы в 1930-е гг. частной компанией Томаша Бати в процессе расширения производственных мощностей. Построенные предприятием для работников красные кирпичные дома ${ }^{3}$ и сейчас остаются отличительной чертой архитектуры Свита. Поскольку строительство по этому проекту компания осуществляла практически во всех странах присутствия, то города-близнецы Свита можно найти в Чехии, Польше, Венгрии и Франции. В Словакии, помимо Свита, этот градостроительный проект реализован в городе Партизанске (в прошлом - Батёваны), возникшем в 1938 г. после того как компания Батя построила на окраине деревни Шимонованы свой завод [9].

\footnotetext{
${ }^{3}$ «Архитектура Батя» представляет собой спаренные коттеджи с собственным садом, которые предоставлялись населению на особых условиях - в частности, жильцам запрещалось сооружать какие-либо пристройки и разводить домашнюю птицу.
} 
Значительная группа монофункциональных поселений России обязана своим развитием эвакуированным во время Великой Отечественной войны предприятиям.

Множество моногородов возникло и в послевоенный период. Так, в Словакии во второй половине XX в. формирование структуры экономики и размещение производственных мощностей проходили согласно принятым в СССР и ЧССР моделям экономического развития. Именно в течение этого периода в Дубнице-над-Вагом ${ }^{4}$ в Детве преимущественно развивалась тяжелая промышленность, а в Тренчине - легкая 6 . В России послевоенный период ознаменовался активным строительством крупных предприятий в малых и средних городах восточной части страны. Значительная часть монофункциональных городов в Польше была создана в соответствии с директивами центральных органов управления после 1945 г. в таких отраслях, как добыча меди и угля, производство стали, химическая и авиационная промышленность. Формирование центров оборонной, нефтегазовой и энергетической отраслей в новых промышленных районах также внесло свой вклад в расширение сети монопрофильных населенных пунктов.

Во всех трех рассматриваемых в статье странах доминирующие компании с момента своего образования осуществляли социальные инвестиции, поддерживая региональное и городское развитие, финансировали культурные и образовательные инициативы. Однако действующие модели социально ответственного поведения имели свои особенности не только в каждой стране, но и в регионе и городе, что было обусловлено потребностями компании, взаимоотношениями с государственными структурами, историческими особенностями. Некоторые предприятия основное внимание уделяли вопросам образования и подготовки трудовых ресурсов на территории своего влияния, другие обеспечивали развитие инфраструктуры и здравоохранения, третьи делали основной акцент на решении экологических проблем. Особенности социально ответственного поведения в каждом случае экономическая теория объясняет наличием у компании множества стейкхолдеров, интересы которых она вынуждена учитывать в своей деятельности [10].

\footnotetext{
${ }^{4}$ Оружейный завод в Дубнице-над-Вагом, созданный в далеком 1928 г., в течение советского периода (вплоть до начала конверсии в 1988 г.) являлся одним из крупнейших предприятий ВПК ЧССР.

5 Завод «Подполянске строярне», производящий военную и строительную технику, был построен в Детве в 1955 г.

${ }^{6}$ В ЧССР новые фабрики швейной отрасли создавались в районах со слабым развитием промышленности, где был излишек рабочей силы, особенно женской Поэтому больше всего было построено в Словакии, на которую приходилось более $1 / 3$ общегосударственного производства ЧССР. Тренчин является одним из основных центров по изготовлению мужской одежды.
}

Характерной чертой российской модели корпоративной социальной ответственности является практика активного государственного участия, когда власть, в условиях недостаточного общественного спроса на социальную активность бизнеса, выступает качестве основного стейкхолдера и использует доступные инструменты принуждения и контроля. Поскольку по своей сути институт социальной ответственности бизнеса является негосударственным, сложившаяся парадоксальная ситуация может провоцировать его нецелевое использование, когда мнимая социальная ответственность бизнеса может служить прикрытием для коррупционных схем или иных нелегальных соглашений между предприятиями и властью. «Добровольнопринудительное» взаимодействие органов власти с компаниями по вопросам социальной ответственности может иметь характер неформального налогообложения, не позволяющего должным образом планировать и контролировать бюджет. Это происходит в том случае, когда участие в финансировании социальных программ осуществляется под угрозой препятствия нормальному функционированию бизнеса, причем преобладание неформальных практик создает условия для пренебрежения общественными интересами в пользу специфических интересов официальных лиц [11].

Достаточно часто отношения бизнеса и государства принимают форму взаимовыгодного обмена или выполнения непосредственных указаний властей. Иногда компании «обменивают» социальные инвестиции на эксклюзивные привилегии, налоговые льготы или субсидии. Договорная модель корпоративной социальной ответственности реализуется в том случае, когда компании и органы государственного управления обладают сопоставимыми ресурсами и влиянием.

Отношения градообразующих предприятий с региональными и местными властями являются в большинстве случаев договорными, однако конкретные условия финансового участия компании в развитии города или региона определяются ее экономическим положением. К примеру, если доминирующая компания вносит существенный вклад в обеспечение занятости населения, а также экономического развития не только города своего размещения, но и всего региона, то развитие и поддержание социальной инфраструктуры и финансирование спортив- 
ных, культурных и образовательных программ осуществляются бизнесом на собственных условиях. Как правило, это относится к монопрофильным городам экспортоориентированных отраслей: нефте- и газодобычи, черной и цветной металлургии, химической и лесной промышленности.

Например, от экономического благополучия Новолипецкого металлургического комбината зависит финансовая стабильность всего региона, значительная часть бюджета которого формируется за счет налогов и других платежей комбината. Так, налоговые и другие обязательные отчисления компании в бюджеты всех уровней (включая внебюджетные фонды) составили в 2015 г. 17,6 млрд руб., причем доля платежей комбината в консолидированный бюджет Липецкой области составила 40\%, а социальные инвестиции - 2,6 млрд руб. (из них на здравоохранение было направлено 43\%, на образовательные и культурные проекты $19 \%$, на развитие спорта - 12\%) [12].

\section{Особенности современного этапа}

Как отмечается на официальном сайте Группы компаний «Норильский никель», большинство ее предприятий имеют статус градообразующих. Следуя принципам социальной ответственности, они вносят значительный вклад в сохранение стабильности на территориях присутствия и в их развитие. Управленческие команды при этом используют достаточно гибкие схемы принятия решений по поводу целесообразности реализации социальных проектов.

Несмотря на сохранение доставшихся в наследство с советских времен патерналистских стереотипов, социально направленная деятельность градообразующих предприятий сегодня значительно отличается от дореформенной практики. Набирает силу процесс реструктуризации социальных инвестиций в соответствии с разработанными долгосрочными и среднесрочными планами развития населенных пунктов; ответственность за реализацию основных мероприятий распределяется между всеми заинтересованными сторонами: властью, градообразующим предприятием, предпринимательским сообществом и местными инициативными группами. Одновременно происходит институциональное оформление деятельности, направленной на поддержку локальных сообществ и устойчивое развитие территории, вырабатываются правила и формы контроля за расходованием выделяемых на социальные цели средств.

За последние годы предприятия «Норильского никеля» выступали с различными инициативными проектами влияния на жизнь городов и регионов своего размещения, что позволило найти новые формы сотрудничества, выгодные обеим сторонам. Так, главные направления взаимодействия ГМК «Норильский никель», вносящей весомый вклад в бюджет Красноярского края, с органами региональной власти и местного самоуправления закреплены в соглашениях о сотрудничестве и реализуются в совместных программах и проектах, сопровождающихся анализом и последующим контролем за эффективностью произведенных затрат (основные из них - «Соглашение по модернизации и развитию объектов социальной, инженерной инфраструктуры и жилищного фонда города Норильска и Таймырского (ДолганоНенецкого) муниципального района на 2011-2020 годы» и «Соглашение по переселению граждан, проживающих в городах Норильске и Дудинке, в районы с благоприятными природноклиматическими условиями на территории РФ на 2011-2020 годы»). Одно из важнейших направлений сотрудничества с региональной и местной властями - природоохранные проекты. Примером такого успешного взаимодействия в экологической сфере является программа «Снижение негативного воздействия на окружающую среду предприятиями Красноярского края на 2014-2020 годы» [13].

Так, важным этапом реализации программы, позволившим существенно снизить выбросы в г. Норильске, стало закрытие Никелевого завода. Для этого потребовалась реконструкция Надеждинского металлургического завода, в результате которой предприятие смогло принять на переработку дополнительное сырье. В Кольской горно-металлургической компании была закрыта агломерационная фабрика. Для этого была запущена линия брикетирования концентрата, что позволило существенно снизить выбросы $\mathrm{SO}_{2}$. Запланированное на следующем этапе улавливание серы (основного компонента выбросов в атмосферу) предполагает изменение технологических процессов на Медном заводе и перенос ряда переделов на Надеждинский. Дальнейшая реализация природоохранной программы (в том числе и закрытие после 2019 г. плавки в поселке Никель 
на Кольском полуострове), по мнению президента «Норникеля» В. Потанина, требует разработки специальных программ с четко прописанными целями и приоритетами в области социального инвестирования, согласования на местном, региональном и федеральном уровнях основных направлений социальной адаптации населения и оптимизации территорий населенных пунктов [14].

Сотрудничество крупного бизнеса с региональными и местными органами власти, а также формы поддержки местного сообщества, которые реализуют в регионах крупные компании, позволяют обеспечить необходимую гибкость государственного регулирования, а также сократить нецелевое применение регулятивных инструментов и информационную асимметрию. Эффективность института корпоративной социальной ответственности как формы коррекции недостатков применения официальных инструментов государственного регулирования и обеспечения необходимого опыта и квалификации для принятия решений в какой-то мере объясняет живучесть феномена гиперответственности градообразующих предприятий России даже в условиях официального освобождения от социальных обязательств.

Как уже отмечалось, ускоренная индустриализация на базе развития тяжелой промышленности на территории Центральной и Восточной Европы в соответствии с долгосрочными программами экономического сотрудничества, специализации и кооперирования стран - членов Совета экономической взаимопомощи во второй половине XX в. привела к формированию сети моногородов. В отличие от России, где новые населенные пункты создавались в малонаселенной части страны, в Словакии новые города развивались рядом с длительно существующими городскими поселениями и агломерациями. Возможно, именно поэтому большинству монофункциональных поселений впоследствии удалось диверсифицировать экономику, и на сегодняшний день городов с единственной доминирующей компанией сохранилось совсем немного.

Однако даже моногородам, успешно реализовавшим потенциал индустриальной диверсификации, требуется государственная поддержка для устранения негативных последствий ускоренной индустриализации, к которым, прежде всего, относятся загрязнение окружающей природной среды и наличие уродующих ландшафты заброшенных промышленных комплексов. Несмотря на многочисленные примеры успешных проектов преобразования промышленных предприятий в крупных европейских городах (в результате которых в зданиях бывших фабрик, водонапорных башень, тюрем, депо, электростанций и пивоварен размещаются комфортабельные гостиницы, художественные и социальные центры), не стоит ожидать массового участия словацких предприятий в масштабных проектах по перепрофилированию индустриальных объектов малых городов. Изменение облика небольших населенных пунктов, повышение их привлекательности как для местных жителей, так и для туризма, требуют привлечения организационных и финансовых ресурсов государства.

Некоторым компаниям и сегодня удалось сохранить в той или иной форме исторически заложенные традиции благотворительной деятельности, что сказалось на степени их социальной ответственности. Такова, например, история словацкого чугунолитейного завода Железярне Подбрезова, инвестиции которого вносили значимый вклад в развитие социальной сферы региона размещения на протяжении всей более чем вековой истории предприятия. На сегодняшний день компания ŽP Group, которой принадлежит производственный комплекс Железярне Подбрезова, является одним из крупнейших производителей металлургической продукции в Центральной Европе, производственные мощности которого размещены в Словакии, Чехии и Испании.

Необходимость работы в замкнутом территориальном пространстве с небольшим притоком трудовых ресурсов извне вынуждает предприятие направлять основные усилия на подготовку и сохранение кадров. Внутренние социальные программы предполагают развитие медицинского обслуживания, оздоровительного отдыха, образования, а также дополнительные социальные и пенсионные выплаты, подарки к праздникам, денежные премии и т.п. Являясь доминирующим игроком на региональном рынке труда, компания обеспечивает не только своих работников, но и все население территории размещения множеством преимуществ, в том числе развитой социальной, жилищно-коммунальной, транспортной и культурно-досуговой инфраструктурой. Хотя на сегодняшний день в Словакии не сложилось жестких моделей социально ответственного поведения градообразующих предприятий, деятельность Железярне Подбрезова в этой области, вне всякого сомнения, отвечает самым высоким международным стандартам.

В других городах страны активно идет диверсификация экономики, создаются новые предприятия и развивается сфера услуг. В частности, структурные изменения экономики Свита и Партизанске, ориентированных ранее на производство обуви, в значительной мере обусловлены уходом компании Батя, которая перенесла свою деятельность в страны с более низкими производственными издержками и утратила лидирующее положение в этих населенных пунктах. Социальные инвестиции предприятий в подобной ситуации, как правило, лежат в плоскости «малых дел» (точечное решение ключевых проблем города, повышение комфортности городской среды и социальной обеспеченности жителей). Большинство мероприятий осуществляется и координируется добровольной ассоциацией социально ответственных компаний, а формы реализации имеют как общие доминанты, так и некоторые специфические акценты, обусловленные локальными экономическими особенностями и механизмом взаимодействия с органами власти. 
В Польше, как и в России, весьма распространены поселения, экономическое положение которых определяется деятельностью одного или нескольких крупных предприятий. В настоящее время децентрализация и возрождение местного самоуправления создают в стране условия для создания института корпоративной социальной ответственности, развивая спрос и осуществляя необходимые для его реализации коллективные действия. Складывается ситуация, когда доминирующая компания перестает отвечать за социальную сферу в широком ее определении (это не относится к решению экологических проблем, оставшихся в ведении предприятий, на территории которых, находятся источники выбросов загрязняющих веществ), однако развитие социальной инфраструктуры все чаще поддерживается косвенно. Как правило, городские органы управления обеспечивают предоставление жилищно-коммунальных, медицинских, образовательных и культурных услуг при значительном финансовом участии домашних хозяйств.

Накопление социального капитала и появление вслед за местным самоуправлением новых акторов - неправительственных организаций, групп местных активистов, индивидуальных видов культурной деятельности - ведет к изменению стратегии социального инвестирования доминирующих компаний, утрате ими лидирующей роли и интеграции в тесную структуру институциональных взаимосвязей. Заметим, что территориальная обособленность градообразующих предприятий может иногда ограничивать взаимодействие на местном уровне.

Польские моногорода пережили нелегкие годы не всегда успешной экономической трансформации. В кризисный период большинство предприятий отказались от затратного содержания непрофильных объектов, ограничив социально ответственное поведение поддержанием занятости.

Коллапс советской экономической модели привел к остановке многих градообразующих предприятий тяжелой и добывающей отраслей, созданных в соответствии с директивами центральных органов управления после 1945 г. Закрытие градообразующих предприятий и отсутствие возможностей для их диверсификации во многих случаях послужили причиной резкого роста безработицы, что в сочетании с низкой мобильностью высвобождаемых работников стало причиной образования депрессивных зон с нарастающей социальной деградацией.

Состояние монофункциональных городов угольной специализации в первую очередь определяется их ресурсной базой. В Валбжихе истощенность запасов привела в середине 1990-х к закрытию угольных шахт. В течение более десяти лет в городе росла безработица и, соответственно, маргинализация жителей. Спасением для города и региона стало создание особой экономической зоны Invest Park, где были размещены предприятия известных компаний, среди которых - Toyota, Takata, Metzeler Automotive HS, Grossman, Faurecia, Glaverbel Silesia, Cersanit.

В то же время многие польские градообразующие предприятия сумели, в основном благодаря иностранным инвестициям, приспособиться к новым экономическим условиям. Примером успешного развития является Белхатув, первоначальное развитие которого было связано с текстильной промышленностью. Открытие залежей бурого угля в 1960-х годах привело к значительным сдвигам в структуре экономики города. Развитие предприятий угольной и энергетической отраслей ${ }^{7}$ обусловило быстрый рост населения. Заботясь о привлечении трудовых ресурсов, градообразующие компании открыли и поддерживают поликлиники и больницу, школы, заботятся об отдыхе, спортивном и культурном развитии населения.

Самым значимым проявлением социально ответственной деятельности предприятий Белхатува является забота об окружающей природной среде. Предприятиями созданы два искусственных озера и искусственная гора из вскрышной породы. На электрической станции действует установка по снижению выбросов диоксида серы, оксидов азота и твердых частиц в атмосферу; ведутся научные исследования, направленные на улучшение технологии. Кроме того, компания участвует в финансировании строительства ветряной электростанции.

Впрочем, активная природоохранная деятельность в какойто степени мера вынужденная - как и любая станция на угле, Белхатувская ТЭС является крупным источником выбросов $\mathrm{CO}_{2}$ в атмосферный воздух. В 2007 г. Всемирный фонд дикой природы

${ }^{7}$ Белхатувская тепловая электростанция является самой крупной ТЭС Евросоюза, а производимая ею электроэнергия составляет $20 \%$ от всей годовой генерации электроэнергии в Польше. 
упомянул электростанцию среди 11 европейских предприятий, оказывающих наиболее интенсивное негативное воздействие на природную среду. А Европейская комиссия в 2014 г. сообщила о самом большом вкладе Белхатувской ТЭС в изменение климата среди европейских предприятий. При поддержке Европейской комиссии на станции осуществляется программа модернизации для сокращения выбросов $\mathrm{CO}_{2}$ путем утилизации углекислоты на нескольких энергоблоках.

Пример Белхатува прекрасно вписывается в характерные для польских монофункциональных поселений схемы социально ответственного поведения доминирующих компаний. Несмотря на некоторые особенности, обусловленные принадлежностью к определенному промышленному сектору, размером компании, степенью влияния на экономику города и размерами населенного пункта, значительная часть социально ответственных акций осуществляется предприятиями отраслей, оказывающих негативное влияние на природную среду (производство стали, целлюлознобумажная отрасль, добыча полезных ископаемых и выработка электроэнергии),

Основным препятствием к осуществлению реформ и диверсификации экономики малых городов Польши является их низкая, в сравнении с более крупными населенными пунктами, привлекательность для потенциальных инвесторов. Кроме того, развитие малого бизнеса в небольших монофункциональных городах из-за ряда причин затруднено, что негативно сказывается на локальном рынке услуг. Однако эти города обладают рядом инвестиционных преимуществ в тех отраслях, где важен эффект масштаба. Последний подразумевает, помимо всего прочего, превалирование и доступность квалифицированных трудовых ресурсов, широкие возможности использования земельных участков и существующих промышленных мощностей.

Одним из драйверов экономического роста в небольших городах с индустриальным потенциалом является средний бизнес, часто дополняющий деятельность доминирующего предприятия, способствуя диверсификации его структуры. Однако наиболее распространенным сценарием трансформации польских моногородов стало перепрофилирование индустриальных объектов с целью осуществления таких видов деятельности, как хранение, коммерция или, иногда, образование. Восстановление производ- ственной функции связано, как правило, с расширением малого и среднего бизнеса, часто стимулируемого деятельностью специальных экономических зон. Развитие на базе доминирующей компании является, скорее, чем-то исключительным, свойственным традиционным отраслям, где имеет место экономия от масштаба производства.

В заключение отметим, что формы социально ответственного поведения на территории рассмотренных посткоммунистических государств отличаются чрезвычайно высокой вариабельностью. Тем не менее в целом наблюдается тенденция постепенного утрачивания градообразующими предприятиями исторически навязанной им роли поставщиков социальной защиты и перехода к добровольному участию в социально-экономическом развитии населенных пунктов и регионах присутствия. Эффективное сотрудничество местных органов управления и бизнеса предполагает совместную разработку социальных и природоохранных программ развития территории присутствия на основе согласованного выбора приоритетов, долевого финансирования и формирования механизмов контроля использования средств.

Становление института социальной ответственности в его истинном понимании требует накопления в обществе критической массы социального капитала - общество должно быть достаточно консолидировано для диалога с доминирующими компаниями. С этой точки зрения представляется весьма интересным опыт Польши, где гражданские инициативы играют важную роль в определении путей социального развития территории.

\section{Литература}

1. Baron D. Private Politics, Corporate Social Responsibility and Integrated Strategy // Journal of Economics and Management Strategy.- 2001.Vol. 10.- № 1.- P. 7-47.

2. Gustafson T. Wheel of Fortune: the Battle for Oil and Power in Russia.Harvard University Press, 2012.

3. Ивантер А., Попов А. Эвтаназия в настоящем продолженном времени // Эксперт Сибирь [Эл. ресурс]. - 2013. - № 15 (371). URL: http:// expert.ru/siberia/2013/15/evtanaziya-v-nastoyaschem-prodolzhennomvremeni/)

4. Блам И. Ю. Тенденции развития нефинансовой отчетности в России // Вопросы статистики.- 2009.- № 5.- С. 41-46. 
5. Моногорода России: как пережить кризис? Анализ социально-экономических проблем моногородов в контексте мирового финансового кризиса, влияющего на состояние градообразующих корпораций. Институт региональной политики.- М., 2008.

6. Brol R. Małe miasta w globalnej wiosce. [in:] Hefner, K., Polko A. (eds.). Transformacja funkcji miejskich w ośrodkach lokalnych.-Katowice: Economic University of Katowice Publishing House, 2010.- P. 15-25.

7. Жога Г. Антикризисная таксономия // Эксперт Урал [Эл. ресурс].2014.- № 42 (619). URL: http://expert.ru/ural/2014/42/antikrizisnayataksonomiya/

8. Samecki W. Centralny Okręg Przemysłowy 1936-1939.- Wrocław: Wydawnictwo Uniwersytetu Wrocławskiego, 1998.

9. Koncitikova G., Gregar A. Corporate Social Responsibility in Bata a.s. from 1894 to 1945 and its Heritage for the Current Business Environment in Advances in Economics, Risk Management, Political and Law Science, Eds D. Pavelkova, J. Strouhal, M. Pasekova, 2012.- P. 130-135.

10. Donaldson T., Preston L. The Stakeholder Theory of the Corporation: Concepts, Evidence and Implications // Academy of Management Review.1995.- Vol. 20.- № 1.- P. 65-91.

11. Чирикова А.Е. Социальная ответственность бизнеса: должник, благодетель, партнер // Наука и образование: хозяйство и экономика; предпринимательство; право и управление.- 2016. - № 4(71).- С. 8-12. 12. URL: http://lipetsk.nlmk.com/ru/responsibility/social-responsibility/ economic-contribution/ (дата обращения: 21.02.2017).

13. URL: http://www.nornik.ru/kompaniya/ustojchivoe-razvitie/ vzaimodejstvie-s-zainteresovannyimi-storonami/sotrudnichestvo-sorganami-vlasti-territorij-prisutstviya-i-obshhestvennyimi-organizacziyami (дата обращения: 21.02.2017).

14. Интервью президента «Норникеля» В. Потанина // Ведомости.- 2016. - № 4229. URL: http://www.nornik.ru/assets/files/2016/ VEDOMOSTI_-VladimirPotanin.pdf (дата обращения: 22.02.2017). 